\title{
Prevalence and risk factors of Syphilis among blood donors of Punjab, Pakistan
}

\author{
Nawaz, Z. ${ }^{1}{ }^{*}$, Rasool, M.H. ${ }^{1}$, Siddique, A.B. ${ }^{1}$, Zahoor, M.A. ${ }^{1}$, Muzammil, S. ${ }^{1}$, Shabbir, M.U. ${ }^{2}$, Javaid, A. ${ }^{1}$, \\ Chaudhry, M. ${ }^{3}$
}

${ }^{1}$ Department of Microbiology, Government College University Faisalabad, Punjab, Pakistan

${ }^{2}$ Medical Laboratory Technician, DHQ Hospital, Mandi Bahauddin, Punjab, Pakistan

${ }^{3}$ Medical Laboratory Technician, DHQ Hospital, Okara, Punjab, Pakistan

*Corresponding author: zeeshannawaz@gcuf.edu.pk

\section{ARTICLE HISTORY}

Received: 5 February 2020

Revised: 22 October 2020

Accepted: 23 October 2020

Published: 25 March 2021

\begin{abstract}
Syphilis is a sexually transmitted disease and its actual prevalence among Pakistani blood donors is currently unknown. A cross sectional study was conducted at different district healthcare hospitals of Punjab, Pakistan with an aim to evaluate the prevalence and risk factors associated with syphilis in blood donors using immunochromatographic test (ICT) and enzyme linked immunosorbent assay (ELISA). A total $(n=1200)$ blood samples were collected from donors aged 18-65 years. All the information regarding personal data, demographic data and risk factors was collected via structured questionnaire. On the basis of ICT and ELISA, the overall prevalence of syphilis was $3.91 \%$ among blood donors. The demographic factors positively linked with syphilis were age $(P=0.000$; Odds ratio, $O R=7.18$; $95 \%$ confidence interval $\mathrm{Cl}=2.816-18.295)$ and education status $(\mathrm{P}=0.000$; Odds ratio, $\mathrm{OR}=$ 12.33; $95 \%$ confidence interval $\mathrm{Cl}=3.469-43.849$ ) of donors. Similarly among the risk factors analyzed, marital status $(P=0.012$; Odds ratio $O R=2.251$; $95 \%$ confidence interval $\mathrm{Cl}=1.206$ $4.202)$ and blood transfusion history $(P=0.030$; Odds ratio $O R=1.981 ; 95 \%$ confidence interval $\mathrm{Cl}=1.083-3.623$ ) were also strongly associated with syphilis. We emphasized the importance of promoting preventive measures for syphilis. The syphilis diagnosis should not be based on a single test. The present study indicates that higher prevalence is alarming for blood donors in Pakistan. Stringent donor screening is highly recommended to ensure maximum safe blood transfusion.
\end{abstract}

Keywords: Prevalence; Risk factors; Syphilis; Blood donors; Pakistan.

\section{INTRODUCTION}

Blood transfusion is a life saving procedure and at the same time, a deadly threat for the recipient because it can also transmit various infectious agents (Allain et al., 2009). Among these, Treponema pallidum is a spirochete bacterial pathogen responsible for a disease named Syphilis. The acquired syphilis is predominantly transmitted through sexual contact and mainly affects the genital and anal area, while the congenital syphilis is transmitted via placenta or hematogenous route (Gomes et al., 2017). The signs associated with primary and secondary syphilis are appearance of painless chancre at the initial site of infection followed by a non-pruritic rash which can resolve spontaneously (Lafond \& Lukehart, 2006). The syphilis can enter in lifelong latency when antibiotic treatment is ignored while $30 \%$ individuals leads to tertiary syphilis with the appearance of gummatous lesions and neurosyphilis (Paulo et al., 2011; Radolf et al., 2016).

According to World Health Organization it is estimated that there are 5.6 million new cases of syphilis globally each year (Newman et al., 2015) and global prevalence is estimated to be 56.1 million (Vos et al., 2017). In recent years the syphilis infections have increased amongst both homosexual and heterosexual individuals in North America, Europe, and Asia (CDC, 2017, de Voux et al., 2017). In females, syphilis rate has increased in middle and high income countries leading to stillbirths in low income nations affected around 1.36 million pregnant women annually (Newman et al., 2013).

The unprotected transfusion of contaminated blood has grievous health consequences in terms of mortality and morbidity. It also produced a significant treatment burden for patients and doctors, while patients become reliant and non-productive (Noubiap et al., 2013). Around 1.5 million transfusions occur annually in Pakistan. The risk of transmission of blood borne infections could be reduced by careful selection and screening of blood donors (Sultan et al., 2007).

Due to the lack of knowledge and being sexually transmitted disease (STD), syphilis is considered as a taboo and Pakistani population is unaware regarding the effects and losses of syphilis. Keeping this in view, the present 
study was planned to estimate the prevalence of Treponema pallidum infection and identification of its possible associated risk factors among the blood donors from different districts of Punjab, Pakistan.

\section{MATERIALS AND METHODS}

\section{Ethical approval}

This study was approved by Institutional Ethical Review Committee under code No: GCUF/ERC/18/03A dated March 30, 2018 and the samples were collected in accordance with international safety rules and biosafety standards. Apparent consents of the patients and objectives of the study were also presented before the patients to keep transparency and avoiding biasness in the study. Furthermore, declaration form was also signed from patients declaring any unhealthy outcomes of the proposed study.

\section{Study Area and Sampling}

Blood samples $(n=1200)$ were collected from blood donors ranging from 18-65 years by means of non-probability-based convenience sampling, during July 2018 and July 2019. The samples were collected from twelve healthcare centers (two from each district) located in different districts of Pakistan, including Faisalabad, Toba Tek Singh, Okara, Sahiwal, Gujranwala and Mandi Bahauddin. A structured questionnaire containing dichotomous questions was designed and presented to each donor at the time of sample collection. The purpose of the questionnaire was to gather information regarding personal details, demographic data and supposed risk factors such as education, occupation, marital status and number of spouse etc. (Ali et al., 2018).

A blood sample of 3-5 ml was collected from each donor in a sterile plastic disposable syringe from cubital vein by a trained laboratory staff member and shifted to gel and clot activator tube which was labeled properly. After half an hour the tube was centrifuged at $3000 \mathrm{rpm}$ for 10 mins to separate serum for diagnostic purpose using Immunuchromatographic test (ICT) and Enzyme linked immunosorbent assay (ELISA).

\section{Serological detection of Treponema pallidum antibodies}

The separated serum samples were screened for antiTreponema pallidum antibodies using Syphilis Ab rapid kit (CTK Biotech, USA) which is a lateral flow chromatographic assay used for the qualitative detection of anti-Treponema pallidum antibodies from human serum (Causer et al., 2014). All the positive samples by ICT method were subjected to ELISA, Syphilis RecombiLISA (CTK Biotech, USA) as per manufacturer's instructions (Karki et al., 2008). The samples that gave positive reactions for both tests were considered as positive due to the variation in the sensitivity and specificity of each test.

\section{Statistical Analysis}

The data obtained was tabulated in a Microsoft Excel spreadsheet and analyzed using Minitab version 18 (LLC software, USA). Descriptive analysis was used to summarize the data on the basis of percentages and chi-square tests.

Bivariate analysis was conducted to establish associations between risk factors and Treponema pallidum infections in blood donors. Odds ratios (OR) were calculated at $95 \%$ confidence intervals $(\mathrm{Cl})$. P-values $<0.05$ were considered to be statistically significant ( $\mathrm{Naz}$ et al., 2018).

\section{RESULTS}

The present study involved 1200 blood donors who were evaluated during the study period for anti-Treponema pallidum antibodies, comprising 1094 males (91.16\%) and 106 females (8.83\%) ranging in age from 18 to 65 years of age. On the basis of age, the donors were divided into three groups: $18-25$ years $(n=615), 25-40$ years $(n=521)$ and $40-65$ years $(n=64)$. Thus, the overall prevalence of Syphilis among blood donors was $3.91 \%(47 / 1200)$.

The prevalence of Syphilis was non-significantly different on the basis of geographical location $(P=0.601)$. It was found to be highest $(5.50 \%)$ in district Okara while the lowest prevalence was observed in the district Toba Tek Singh $(2.50 \%)$ as shown in Table 1 . On the basis of residences, blood donors living in rural areas were more prone to Syphilis $(4.06 \%)$ than those living in urban areas $(3.71 \%)$. These results were also non-significant $(P>0.05)$. The blood donors having higher educational status showed lower prevalence rate of Syphilis $[(\mathrm{P}=0.000), \mathrm{OR}=12.33,95 \% \mathrm{Cl}=3.469-43.849]$. In contrast, the rate of susceptibility to Syphilis was highest $(12.50 \%)$ among the donors of age range $40-65$ years than among those in the age range $25-40$ years $(5.18 \%)$ and $18-25$ years $(1.95 \%)[(P=0.000), O R=7.18,95 \% C l=2.816-18.295]$. On the basis of gender, the prevalence of Syphilis in male and female blood donors was $11.40 \%(43 / 1094)$ and $7.50 \%$ (4/106), respectively. There was no significant variation in the prevalence of Syphilis with regard to gender $(P>0.05)$. Among different occupations, the prevalence of syphilis was found highest in business men blood donors (5.88\%) while the lowest percentage was detected in shopkeepers $(2.35 \%)$ as shown in (Table 2).

The prevalence of Syphilis was statistically significant on the basis of marital status and blood transfusion history. It was found much higher in married donors as compared to singles $[(\mathrm{P}=0.012), \mathrm{OR}=2.251,95 \% \mathrm{Cl}=1.206-4.202]$. Similarly, the prevalence was $6.14 \%$ in those who got blood transfusions previously in their lives in contrast to those who didn't get any transfusion in their lifespan 3.19\% [( $P=0.030), O R=1.981$ $95 \% \mathrm{Cl}=1.083-3.623]$. Statistically, there was no significant variation in the prevalence of Syphilis in blood donors with reference to number of spouse and blood donation history $(\mathrm{P}>0.05)$ as shown in (Table 3 ).

Table 1. Prevalence of Syphilis among blood donors in different districts in Pakistan

\begin{tabular}{|c|c|c|c|c|}
\hline Area & $\begin{array}{c}\text { Total } \\
\text { Sampled }\end{array}$ & $\begin{array}{c}\text { Total } \\
\text { Positive }\end{array}$ & $\begin{array}{c}\text { Prevalence } \\
(\%)\end{array}$ & $\mathrm{P}$ Value \\
\hline Faisalabad & 200 & 10 & $05.00 \%$ & \\
\hline Toba Tek Singh & 200 & 05 & $02.50 \%$ & \\
\hline Okara & 200 & 11 & $05.50 \%$ & \\
\hline Sahiwal & 200 & 07 & $03.50 \%$ & 0.601 \\
\hline Gujranwala & 200 & 08 & $04.00 \%$ & \\
\hline Mandi Bahauddin & 200 & 06 & $03.00 \%$ & \\
\hline Total & 1200 & 47 & $03.91 \%$ & \\
\hline
\end{tabular}


Table 2. Prevalence of Syphilis in blood donors according to demographic factors

\begin{tabular}{|c|c|c|c|c|c|}
\hline Risk factors & $\mathrm{N}$ & Positive (\%) & P Value & Odds Ratio & $95 \% \mathrm{Cl}$ \\
\hline \multicolumn{6}{|l|}{ Residency (1200) } \\
\hline Urban & 512 & $19(3.71 \%)$ & 0.760 & 1.100 & $(0.607-1.994)$ \\
\hline Rural & 688 & $28(4.06 \%)$ & & & \\
\hline \multicolumn{6}{|l|}{ Gender (1200) } \\
\hline Male & 1094 & $43(11.40 \%)$ & 0.939 & 1.04 & $(0.367-2.965)$ \\
\hline Female & 106 & $04(7.50 \%)$ & & & \\
\hline \multicolumn{6}{|l|}{ Age (1200) } \\
\hline $18-25$ Years & 615 & $2(1.95 \%)$ & & & \\
\hline $25-40$ Years & 521 & $127(5.18 \%)$ & 0.000 & 2.74 & $(1.377-5.477)$ \\
\hline 40-65 Years & 064 & $08(12.50 \%)$ & & 7.18 & $(2.816-18.295)$ \\
\hline \multicolumn{6}{|l|}{ Education status (1200) } \\
\hline Graduate & 262 & $03(01.14 \%)$ & & & \\
\hline Intermediate & 188 & $06(03.19 \%)$ & & 2.84 & $(0.702-11.528)$ \\
\hline Secondary & 408 & $14(03.43 \%)$ & 0.000 & 3.06 & $(0.873-10.780)$ \\
\hline Primary & 232 & $10(04.31 \%)$ & & 3.88 & $(1.057-14.307)$ \\
\hline Uneducated & 112 & $14(12.50 \%)$ & & 12.33 & (3.469-43.849) \\
\hline \multicolumn{6}{|c|}{ Occupation Status (1200) } \\
\hline Shopkeeper & 254 & $06(02.35 \%)$ & & & \\
\hline Student & 223 & $06(02.69 \%)$ & & 1.14 & $(0.363-3.595)$ \\
\hline Private Job & 082 & $03(03.65 \%)$ & & 1.56 & $(0.383-6.421)$ \\
\hline Farmer & 182 & $08(04.39 \%)$ & 0.364 & 1.90 & $(0.647-5.574)$ \\
\hline Government Job & 043 & $02(04.65 \%)$ & & 2.01 & $(0.393-10.332)$ \\
\hline Labour & 256 & $13(05.07 \%)$ & & 2.21 & $(0.827-5.911)$ \\
\hline Unemployed & 058 & $03(05.17 \%)$ & & 2.25 & $(0.546-9.293)$ \\
\hline Businessman & 102 & $06(05.88 \%)$ & & 2.58 & $(0.813-8.206)$ \\
\hline
\end{tabular}

Table 3. Prevalence of infection in blood donors according to risk factors

\begin{tabular}{|c|c|c|c|c|c|}
\hline Risk factors & $\mathrm{N}$ & Positive (\%) & P-Value & Odds Ratio & $95 \% \mathrm{Cl}$ \\
\hline \multicolumn{6}{|l|}{ Married (1200) } \\
\hline Yes & 593 & $32(05.39 \%)$ & 0.012 & 2.251 & $(1.206-4.202)$ \\
\hline No & 607 & $15(02.47 \%)$ & & & \\
\hline \multicolumn{6}{|l|}{ No of Spouse (593) } \\
\hline One & 538 & $27(05.01 \%)$ & 0.234 & 1.892 & $(0.698-5.131)$ \\
\hline More than one & 055 & 05 (09.09\%) & & & \\
\hline \multicolumn{6}{|c|}{ Blood Transfusion (1200) } \\
\hline Yes & 293 & $18(06.14 \%)$ & 0.030 & 1.981 & $(1.083-3.623)$ \\
\hline No & 907 & 29 (03.19\%) & & & \\
\hline \multicolumn{6}{|c|}{ Blood Donation (1200) } \\
\hline Yes & 481 & $16(03.32 \%)$ & 0.406 & 0.763 & $(0.413-1.412)$ \\
\hline No & 719 & 31 (04.31\%) & & & \\
\hline
\end{tabular}

\section{DISCUSSION}

Pakistan is confronting with the availability of safe and efficacious blood to donate, leading to its increased demand, elevating rate of transfusion transmissible infections, inadequate screening and suboptimal blood transfusion facilities (Sultan et al., 2016). The current study determined the prevalence of syphilis among the blood donors of different districts of Punjab, Pakistan and the potential risk factors associated with this infection. The overall prevalence of syphilis was $3.91 \%$. On the basis of geographical area, the difference in the prevalence of syphilis in blood donors was statistically non significant which is an indication that infection is present equally in all districts of Punjab, Pakistan. The findings of our study are close to the results of $3.1 \%$ in Lahore (Nazir et al., 2013) and $2.1 \%$ in Karachi (Arshad et al., 2016) while our results are much greater than the previous observations of $0.91 \%$ in Karachi (Sultan et al., 2016), 1.55\% and 1.1\% in Lahore (Saeed et al., 2017) and (Ahmad et al., 2019) respectively. This variation in the prevalence is probably due to differences in the socioeconomic status, availability of proper blood screening, transfusion and medical facilities between different districts. Furthermore, the increase in unprotected sexual contacts and misuse of contaminated syringes are aggravating the situation in Pakistan.

The residential areas also affect the prevalence of syphilis among blood donors as it was found elevated in 
rural area donors $4.06 \%$ in contrast to donors of urban areas $3.71 \%$ and these results also resembles with previous studies (Bisseye et al., 2013; Arshad et al., 2016; Negash et al., 2018; Keleta et al., 2019). Male donors were at higher risk of syphilis $(11.40 \%)$ than female donors $(7.50 \%)$. These results are in accordance with previously conducted researches in Pakistan (Arshad et al., 2016; Saeed et al., 2017; Amin et al., 2019), Brazil (Gomes et al., 2017), Nepal (Karki et al., 2008) and Eritrea (Keleta et al., 2019). These results might be due to lack of education and proper blood screening practices in rural health centers, while the males are more prone to syphilis infection because they are at higher risk of roadside accidents and mechanical injuries hence needs more blood transfusions. In additions, the trend of blood donation is more pronounced in males as compared to females in our society.

The role of age was found statistically associated with the sero-prevalence of syphilis as it was highest $(12.50 \%)$ in age group (40-65 years). These results are in accordance with the findings of (Karki et al., 2008; Mutagoma et al., 2016; Keleta et al., 2019). As the age increases, the chances of exposure to infection \& transfusion increases as well as the immune system efficacy decreases leading to increased likelihood towards syphilis. On the basis of occupation, the percentage of syphilis infection was found highest in businessmen and labor/unemployed individuals. These results are in accordance with previous work of (Arshad et al., 2016; Keleta et al., 2019). In the current study an inverse relationship was found between prevalence of syphilis and educational status. The percentage of syphilis was highest in uneducated donors (12.5\%) while the lowest was observed in graduates $(1.14 \%)$ corresponding with the previous studies (Kane et al., 2015; Mutagoma et al., 2016; Gomes et al., 2017; Keleta et al., 2019). These findings highlighted the need to improve the health education among the population. The low literacy level in Pakistan, cultural reticence for sex education and hesitating behavior towards use of condoms are the reasons behinds such type of observations.

Among the risk factors, marital status $[P=0.012 ; O R=2.251$ (95\% Cl= 1.206-4.202)] and blood transfusion $[P=0.030$; $O R=$ $1.981(95 \% \mathrm{Cl}=1.083-3.623)]$ are statistically associated with syphilis among blood donors. These findings also resemble with the results of (Arshad et al., 2016; Halakoto et al., 2017; Banong-le et al., 2019). The culture and norms of not screening the partners for sexually transmitted diseases before marriage leads to transmission of these diseases including syphilis to the married couples. Similarly lack of good blood screening and transfusion facilities makes the transfusions risky for the recipients. The donors having more than one spouse or sexual partners had 1.8 times more chances of getting syphilis infection which was also endorsed by the findings of (Mutagoma et al., 2016) as unprotected sex and multiple partners are considered as major risk towards syphilis (Casal et al., 2011).

\section{CONCLUSION}

The results of our study concluded that prevalence of syphilis among blood donors is increasing and an alarming situation for public health. The factors strongly associated with syphilis were age, education, marital status and blood transfusions. This increasing trend of syphilis infections can be restrained by its early diagnosis, proper treatment, promotion of condom-use and education regarding sex as control strategies. There is an essential need for stringent donor selection with the emphasis on getting voluntary donations and comprehensive screening of donor's blood for Syphilis and other TTI's to safeguard the blood recipients.

\section{Conflict of interest}

The authors declare that there is no conflict of interest.

\section{REFERENCES}

Ahmad, M., Saeed, M., Hanif, A., Waheed, U., Arshad, M., Ain, N.U., Rasheed, F. \& Hussain, S. (2019). Slump of Trends in TransfusionTransmissible Infectious Diseases: Is Syphils Alarming in Pakistan? Global Journal of Transfusion Medicine 4(1): 45-51.

Ali, S., Nawaz, Z., Akhtar, A., Aslam, R., Zahoor, M.A. \& Ashraf, M. (2018). Epidemiological Investigation of Human Brucellosis in Pakistan. Jundishapur Journal of Microbiology 11(7): e61764. https://doi.org/10.5812/jjm.61764

Allain, J.P., Stramer, S.L., Carneiro-Proietti, A., Martins, M. \& Lopes, S.S. (2009). Transfusion-transmitted infectious diseases. Biologicals 37(2): 71-77. https://doi.org/10.1016/ j.biologicals.2009.01.002

Amin, H., Jafar, H.S., Sadiq, F., Bhatti, S., Ahmad, N., Gul, S. \& Lodhi, Y. (2019). Prevalence of Syphilis among the Healthy Blood Donors - A Hospital based Retrospective Study. Pakistan Journal of Medical and Health Sciences 13(3): 647649.

Arshad, A., Borhany, M., Anwar, N., Naseer, I., Ansari, R., Boota, S., Fatima, N., Zaidi, M. \& Shamsi, T. (2016). Prevalence of transfusion transmissible infections in blood donors of Pakistan. BMC Hematology 16(1): 27-32. https://doi.org/ 10.1186/s12878-016-0068-2

Banong-le, M., Ofosu, S.K. \& Anto, F. (2019). Factors associated with syphilis infection: a cross-sectional survey among outpatients in Asikuma Odoben Brakwa District, Ghana. BMC Infectious Diseases 19(1): 360-368. https://doi.org/ 10.1186/s12879-019-3967-6

Bisseye, C., Sanou, M., Nagalo, B.M., Kiba, A., Compaoré, T.R., Tao, I. \& Simpore, J. (2013). Epidemiology of Syphilis in regional blood transfusion centres in Burkina Faso, West Africa. Pan African Medical Journal 16(1): 69-76. https://doi. org/10.11604/pamj.2013.16.69.2767

Casal, C.A.D., Silva, M.O., Costa, I.B., Araújo, E.C. \& Corvelo, T.C.O. (2011). Molecular detection of Treponema pallidum sp. pallidum in blood samples of VDRL-seroreactive women with lethal pregnancy outcomes: A retrospective observational study in northern Brazil. Revista da Sociedade Brasileira Medicina Tropical 11(1): 1-5.

Causer, L.M., Kaldor, J.M., Fairley, C.K., Donovan, B., Karapanagiotidis, T., Leslie, D.E., Robertson, P.W., McNulty, A.M., Anderson, D., Wand, H., Conway, D.P., Denham, I., Ryan, C. \& Guy, R.J. (2014). A Laboratory-Based Evaluation of Four Rapid Point-of-Care Tests for Syphilis. PLOS One 9(3): e91504. https://doi.org/10.1371/journal.pone.0091504

Centers for Disease Control and Prevention. (2017). Sexually transmitted diseases surveillance. https://www.cdc.gov/ std/stats16/natoverview.htm

de Voux, A., Kidd, S., Grey, J.A., Rosenberg, E.S., Thomas, L.G., Weinstock, M.D. \& Bernstein, K.T. (2017). State-specific rates of primary and secondary syphilis among men who have sex with men-United States, 2015. Morbidity and Mortality Weekly Report 66(13): 349-354. https://doi.org/ 10.15585/mmwr.mm6613a1

Gomes, N.C.R.C., Meier, D.A.P., Pieri, F.M., Alves, E., Albanese, S.P.R., Lentine, E.C., Arcêncio, R.A. \& Dessunti, E.M. (2017). Prevalence and factors associated with syphilis in a Reference Center. Revista da Sociedade Brasileira Medicina 
Tropical 50(1): 27-34. https://doi.org/10.1590/0037-86820102-2016

Halatoko, W.A., Landoh, D.E., Saka, B., Akolly, K., Layibo, Y., Yaya, I., Gbetoglo, D., Bania, A.K. \& Pitche, P. (2011). Prevalence of syphilis among female sex workers and their clients in Togo in 2011. BMC Public Health 17(1): 219223. https://doi.org/10.1186/s12889-017-4134-x

Kane, M.A., Bloch, E.M., Bruhn, R., Kaidarova, R. \& Murphy, E.L. (2015). Demographic determinants of syphilis seroprevalence among U.S. blood donors, 2011-2012. BMC Infectious Diseases 15(63): 1-9. https://doi.org/10.1186/ s12879-015-0805-3

Karki, S., Tiwari, B.R., Ghimire, P., Maharjan, A. \& Rajkarnikar, M. Seroprevalence of Specific Antibodies to Treponema pallidum in Blood Donors. Journal of Nepal Health Research Council 6(13): 98-101.

Keleta, Y.T., Achila, O.O., Haile, A.W., Gebrecherkos, B.H., Tesfaldet, D.T., Teklu, K.S., Mohammed, M.A. \& Ghedel, S.T. (2019). Seroprevalence of transfusion transmitted infections among blood donors in Gash Barka Zonal Blood Transfusion Center, Barentu, Eritrea, 2014 through 2017. BMC Hematology 19(5): 1-9. https://doi.org/10.1186/ s12878-019-0136-5

Lafond, R.E. \& Lukehart, S.A. (2006). Biological basis for syphilis. Clinical Microbiology Reviews 19(1): 29-49. https:// doi.org/10.1128/CMR.19.1.29-49.2006

Mutagoma, M., Remera, E., Sebuhoro, D., Kanters, S., Riedel, D.J. \& Nsanzimana, S. (2016). The Prevalence of Syphilis Infection and Its Associated Factors in the General Population of Rwanda: A National Household-Based Survey. Journal of Sexually Transmitted Diseases 2016: 4980417. https://doi.org/10.1155/2016/4980417

Naz, A., Nawaz, Z., Rasool, M.H. \& Zahoor, M.A. (2018). Crosssectional epidemiological investigations of Giardia lamblia in children in Pakistan. Sao Paulo Medical Journal 136(5): 449-453. https://doi.org/10.1590/1516-3180.2018. 0350060918

Nazir, S., Pracha, H.S., Khan, A., Nazar, A., Fayyaz, A. \& Khan, M.S. (2013). Prevalence of syphilis in Pakistani blood donors. Advancements in Life Sciences 1(1): 27-30.

Negash, M., Wondmagegn, T. \& Geremew, D. (2018). Comparison of RPR and ELISA with TPHA for the Diagnosis of Syphilis: Implication for Updating Syphilis Point-of-Care Tests in Ethiopia. Journal of Immunology Research 2018: 2978419. https://doi.org/10.1155/2018/2978419

Newman, L., Kamb, M., Hawkes, S., Gomez, G., Say, L., Seuc, A. \& Broutet, N. (2013). Global estimates of syphilis in pregnancy and associated adverse outcomes: Analysis of multinational antenatal surveillance data. PLoS Medicine 10(2): e1001396. https://doi.org/10.1371/journal.pmed. 1001396

Newman, L., Rowley, J., Vander, H.S., Wijesooriya, N.S., Unemo, M. \& Low, N. (2015). Global estimates of the prevalence and incidence of four curable sexually transmitted infections in 2012 based on systematic review and global reporting. PLoS One 10(12): e0143304. https://doi.org/ 10.1371/journal.pone.0143304

Noubiap, J.J.N., Joko, W.Y.A., Nansseu, J.R.N., Tene, U.G. \& Siaka, C. (2013). Sero-epidemiology of Human Immunodeficiency Virus, hepatitis B and C viruses, and syphilis infections among first-time blood donors in Edéa, Cameroon. International Journal of Infectious Diseases 17(10): e832e837. https://doi.org/10.1016/j.ijid.2012.12.007
Paulo, N., Cascarejo, J. \& Vouga, L. (2011). Syphilitic aneurysm of the ascending aorta. Interactive Cardiovascular and Thoracic Surgery 14(2): 223-225. https://doi.org/10.1093/ icvts/ivr067

Radolf, J.D., Deka, R.K., Anand, A., Smais, D., Norgard, M.V. \& Yang, X.F. (2016). Treponema pallidum, the syphilis spirochete: making a living as a stealth pathogen. Nature Reviews Microbiology 14(12): 744-759. https://doi.org/ 10.1038/nrmicro.2016.141

Saeed, M., Hussain, S., Rasheed, F., Ahmad, M., Arif, M. \& Rahmani, M.T.H. (2017). Silent killers: Transfusion transmissible infections TTI, among asymptomatic population of Pakistan. Journal of Pakistan Medical Association 67(3): 369374.

Sultan, S., Murad, S. \& Irfan, S.M. (2016). Trends of venereal infections among healthy blood donors at Karachi. Archives of Iranian Medicine 19(3): 192-196.

Vos, T., Abajobir, A.A., Abate, K.H., Abbafati, C., Abbas, K.M. \& Abd-Allah, F. (2017). Global, regional, and national incidence, prevalence, and years lived with disability for 328 diseases and injuries for 195 countries, 1990-2016: a systematic analysis for the global burden of disease study 2016. Lancet 390(10100): 1211-1259. https://doi.org/ 10.1016/S0140-6736(17)32154-2 